\title{
Nucleolus contains signal molecules that constitute membrane-nucleolus linked pathway
}

\author{
Jin-Sook Jeong ${ }^{1}$, In-Hoo Kim ${ }^{1}$, Hye-Jeong Lee ${ }^{1}$ \\ and Yong-Chun Choi ${ }^{1,2}$ \\ 1 Life Science Research Institute, Dong-A University College of Medicine, Pusan 602- \\ 103, Korea \\ 2 Corresponding author: Tel, 82-51-240-2930; Fax, 82-51-241-0778 \\ E-mail, ycchoi@seunghak.donga.ac.kr
}

Accepted 15 September 1998

Abbreviations: DAG, diacylglyceride; $\mathrm{IP}_{3}$, inositol triphosphate; $\mathrm{CK} 2$, casein kinase 2; PKA, protein kinase A; PKC, protein kinase C; GPCR, G protein coupled receptor; TA, thioacetamide

\begin{abstract}
Since there have been very few studies on nucleolar signaling, an attempt was made to establish nucleolar signal pathways which link the cell membrane to the nucleolus for the transfer of extracellular signals. Two pathways were studied. One was the Gos mediated cAMP pathway where two signal molecules were yielded, including $R_{\| l}$ and protein kinase $A$. The other was the G $\alpha q$ mediated $\mathrm{DAG} / \mathrm{P}_{3}$ pathway which yields two signals including protein kinase $C$ and $\mathrm{IP}_{3} / \mathrm{Ca}^{2+}$. By the studying isolated nucleoli from resting liver, regenerating liver or weak carcinogen thioacetamide treated liver, it was possible to detect protein kinase A (PKA), protein kinase C (PKC) and $R_{\|}$subunits. In addition, CK2 was detected. It was found that external signals transmitted through $G$ protein coupled recep-tors could reach into the nucleolus and that physical translocation of signal molecules was an integral step involved in membrane-nucleolus linked pathways. When an in vitro assay of the above signal molecules was carried out using $\left[\gamma-{ }^{32} \mathrm{P}\right]-\mathrm{ATP}$, most kinase dependent phosphorylation was via the major CK2 (more than 95\%). Therefore, it is suggested that the major CK2 dependent pathway is involved in 'house keeping' for nucleolar integrity and the minor pathways, dependent on PKA, PKC and others, are involved in subtle regulatory mechanisms such as 'extra-house-keeping' activities by nucleolar chromosomal remodeling.
\end{abstract}

Keywords: Nucleolus, Thioacetamide, Signal transduction

\section{Introduction}

The cell nucleus has three transcriptional substructures where pol I dependent transcription is solely performed in the nucleolus, while pol II and pol III dependent transcriptions take place in the nucleoplasm. Being the site of pol I dependent ribosome genesis, the mammalian nucleolus contains a number of post-translational modification mechanisms involved in the activation-deactivation cycle related to the regulation of nucleolar ribosome genesis. These mechanisms are protein methylation (Lischwe et al, 1985), acetylation (Goldknopf et al, 1979), ubiquitination (Goldknopf and Busch, 1978), phosphorylation (Olson et al, 1974), adduct formation to RNA (Ahn et al, 1985) and others (Busch, 1997). Among these molecular mechanisms, protein phosphorylation is a major modification process involved in the regulation of nucleolar function. In earlier works using [ $\left.{ }^{32} \mathrm{P}\right]$-labeling techniques of tissue culture, three major nucleolar phosphoproteins were defined. These were $38 \mathrm{kDa}$ nucleophosmin, $110 \mathrm{kDa}$ nucleolin and $140 \mathrm{kDa}$ Nopp140 (Ahn et al, 1985). More recently, sequence studies of various nucleolar proteins made it possible to define a dozen species of nucleolar phosphoproteins (Busch, 1997).

Recently, an extensive effort has been made to characterize the mechanism of kinase dependent nucleolar protein phosphorylation involved in various biological conditions. Despite the fact that the research area of signal transduction has advanced enormously as a whole, there were very few studies of the nucleolar signaling system compared to the nuclear signaling system (Meck and Street, 1992; Inagaki et al, 1994; Buchner, 1995; Diehl and Rai, 1996). Thus, this effort has been directed to focus on the characterization of nucleolar signal cascades or pathways operative in a cell. Research was performed to describe types of phosphoproteins, their motif specific protein kinases and the organization of a signal cascade, composed of cellular kinases, for the genesis of ribosomes. With an accumulated catalogue, it would be possible to assign the regulatory roles of phosphorylation to trans-cription in the dense fibrillar component and fibrillar centers, snoRNA dependent processing in the granular component, and import/export of nucleolar components for maintenance of functional integrity (Busch, 1997). It has been indicated that all the nucleolar phosphoproteins described possess the casein kinase 2 motif and this kinase is the utmost important signal molecule in ribosome genesis (Table 1). 
Table 1. A catalogue of observed nucleolar phosphoproteins compared with published findings. Based on compiled findings (Busch, 1997) and our unpublished results, comments were made. Motifs listed are from computer searches (http://expasy.hcuge.ch/sprot/scnpsit1.html). (v) denotes variations in experimental findings.

\begin{tabular}{|c|c|c|c|c|c|}
\hline \multicolumn{2}{|c|}{$\begin{array}{l}\text { Observed labelling } \\
\text { nucleolar } \\
\text { phosphoproteins } \\
(\mathrm{MW} / \mathrm{kDa})\end{array}$} & \multicolumn{3}{|c|}{ Kinase motifs } & \multirow[t]{2}{*}{ Comments } \\
\hline $\begin{array}{c}\text { Novikoff } \\
\text { hepatoma }\end{array}$ & $\begin{array}{c}\text { TA treated } \\
\text { hepatocytes }\end{array}$ & CK2 & PKC & PKA & \\
\hline 180 & $180(v)$ & + & + & + & DNA topoisomerase II $\beta(180 \mathrm{kDa})$ \\
\hline 140 & $140(v)$ & + & + & + & Nopp 140 \\
\hline 130 & $130(v)$ & $\begin{array}{l}+ \\
+\end{array}$ & $\begin{array}{l}+ \\
+\end{array}$ & $\begin{array}{l}+ \\
+\end{array}$ & $\begin{array}{l}\text { p130 } \\
\text { RNA pol I (127 kDa) }\end{array}$ \\
\hline 120 & $120(v)$ & + & + & + & p120 \\
\hline $\begin{array}{l}110 \\
100\end{array}$ & 110 & $\begin{array}{l}+ \\
+ \\
+\end{array}$ & $\begin{array}{l}+ \\
+ \\
+\end{array}$ & $\begin{array}{l}+ \\
+\end{array}$ & $\begin{array}{l}\text { Nucleolin }(110 \mathrm{kDa}) \\
\text { pRb (110 kDa) } \\
\text { Gu protein }(96 \mathrm{kDa})\end{array}$ \\
\hline 90 & 90 & $\begin{array}{l}+ \\
+\end{array}$ & $\begin{array}{l}+ \\
+\end{array}$ & + & $\begin{array}{l}\text { UBF-1 }(92 \mathrm{kDa}) \\
\text { DNA topoisomerase I (92 kDa) }\end{array}$ \\
\hline 85 & & & & & $?$ \\
\hline 78 & & & & & $?$ \\
\hline 73 & & & & & $?$ \\
\hline 65 & 63 & + & + & + & Coilin (63 kDa) \\
\hline 53 & & + & + & & p53 (53 kDa) \\
\hline 45 & 48 & + & + & & RNA helicase (49 kDa) \\
\hline 40 & 43 & & & & $?$ \\
\hline 36 & 39 & + & + & + & Nucleophosmin (38 kDa) \\
\hline 34 & 35 & + & + & + & Fibrillarin (34 kDa) \\
\hline 32 & 32 & & & & $?$ \\
\hline 24 & 25 & & & & $?$ \\
\hline 22 & & & & & $?$ \\
\hline 21 & 19 & & & & $?$ \\
\hline
\end{tabular}

In the present report, an attempt was made to establish the presence of nucleolar signal cascades which constitute a signal pathway from the membrane receptor to the nucleolus. To demonstrate links between the cell membrane and the nucleolus, $\mathrm{G} \alpha$ protein mediated signal molecules such as protein kinase A (PKA) and protein kinase $C$ (PKC) were examined in various biological states of hepatocyte nucleoli. To perform experimental analysis, nucleoli were isolated from normal rat liver, regenerating rat liver, carcinogenic thioacetamide treated rat liver or rapidly dividing Novikoff hepatoma. From the different nucleolar preparations, above signal molecules were analyzed. It was found that $\mathrm{G} \alpha$ protein mediated kinases were readily observed in the various nucleolar preparations.

\section{Materials and Methods}

\section{Animals}

Male Sprague Dawly rats were fed with labchow and water ad libitum. Their body weights were approximately $200 \mathrm{~g}$. Partial hepatectomy was performed according to the method described by Higgins and Anderson (1931). Daily thioacetamide (TA) treatment $(50 \mathrm{mg} / \mathrm{kg})$ was given according to the method previously published (Kleinfeld, 1952).

\section{Reagents and materials}

Most chemicals were obtained from Sigma. Fetal bovine serum, MEM and antibiotics were from GIBCO/BRL, U.S.A. Antibodies were obtained for nucleophosmin from Dr. P.K. Chan, and from Dr. H. Busch for nucleolin, UBI for PKC (77 kDa subunit) and casein kinase 2 (40-44 kDa $\alpha / \alpha^{\prime}$ subunit); and from Dr. M. Muramatsu for PKA (40 kDa $C$ subunit). Both carrier free $\left[{ }^{32} \mathrm{P}\right]$-phosphate and $\left.{ }^{32} \mathrm{P}\right]$-azido cAMP were obtained from ICN. Protein kinase inhibitors were obtained from UBI. 


\section{Tissue culture}

Novikoff hepatoma cells were grown as a monolayer using DMEM $/ 10 \%$ fetal bovine serum in a $5 \% \mathrm{CO}_{2}$ atmosphere at $37^{\circ} \mathrm{C}$. The grown cells were harvested by trypsinization when $90 \%$ confluency was reached.

\section{Preparation of nucleoli}

Nucleoli were isolated from livers obtained from normal rats, post-hepatectomized rats and thioacetamide-treated rats. The livers were first perfused with physiological saline to remove red cells and Novikoff hepatoma cells were harvested after trypsinization. Subsequently, the livers or tumour cells were homogenized in $2 \mathrm{M}$ sucrose containing $3.3 \mathrm{mM}$ Calcium acetate and then nuclei were isolated by centrifugation. Nucleoli were isolated by disruption of neclei using a sonication method followed by differential centrifugation (Busch, 1967). The experiment was performed in a cold room at $4^{\circ} \mathrm{C}$ and all solutions contained proteolysis inhibitors ( $1 \mathrm{mM}$ PMSF, 5 $\mu \mathrm{g} / \mathrm{ml}$ aprotinin, $5 \mu \mathrm{g} / \mathrm{ml}$ leupeptin, $1 \mathrm{mM}$ benzamidine, $0.1 \mathrm{mM}$ pepstatin and $0.1 \mathrm{mM}$ antipain).

\section{Labeling experiments}

When Novikoff hepatoma cells were labeled with inorganic [ $\left.{ }^{32} \mathrm{P}\right]$-phosphate $\left(5 \mathrm{mCi} / 150 \mathrm{~cm}^{2} \mathrm{~T}\right.$ flask), phosphate free MEM was used for overnight growth and efficient labeling (Ahn et al, 1985). After harvesting, nucleoli were isolated by the method described by Busch (1967). To label nucleolar phosphoproteins under in vitro conditions, isolated nucleoli from various liver preparations and Novikoff hepatoma cells were incubated with $\left[\gamma^{32} \mathrm{P}\right]$-ATP at $30^{\circ} \mathrm{C}$ for $20 \mathrm{~min}$. The composition of buffer used contained 20 mM MOPS ( $\mathrm{pH} 7.2$ ), 25 mM $\beta$-glycerol phosphate, 5 mM EGTA, $1 \mathrm{mM}$ sodium vanadate, $1 \mathrm{mM}$ dithiothreitol and $18 \mathrm{mM}$ magnesium chloride (Bagrodia et al., 1995). Also, various protease inhibitors were included (1 mM PMSF, $5 \mu \mathrm{g} / \mathrm{ml}$ aprotinin, $5 \mu \mathrm{g} / \mathrm{ml}$ leupeptin, $1 \mathrm{mM}$ benzamidine, $0.1 \mathrm{mM}$ pepstatin and $0.1 \mathrm{mM}$ antipain).

\section{Analysis of regulatory subunits of protein kinase A}

$\mathrm{R}$ subunits were extracted from nucleoli using a buffer containing $0.1 \mathrm{M} \mathrm{NaCl}, 5 \mathrm{mM} \mathrm{MgCl} 2,1 \%$ Nonidet P-40, $0.5 \%$ sodium deoxycholate, $20 \mathrm{mM}$ Tris- $\mathrm{HCl}(\mathrm{pH}$ of 7.4$)$. The extract was incubated with $\left[{ }^{32} \mathrm{P}\right]$-azido-cAMP and irradiated for $30 \mathrm{sec}$ under a short wavelength UV lamp for crosslinking with the R subunit (Tortora et al., 1990).

\section{SDS-polyacrylamide gel electrophoresis and Western blotting}

Proteins were fractionated in a $10 \%$ SDS-polyacrylamide gel (Laemmli, 1970). Subsequently, the separated proteins were transferred to nitrocellulose according to the method described by Towbin et al. (1979). With the transferred proteins on nitrocellulose, Western blotting analysis was done using various antibodies.

\section{Determination of phospho-amino acids}

Bulk phosphoproteins were subjected to acid hydrolysis and the resultant phosphoamino acids were separated by high voltage electrophoresis (Ahn et al, 1985). In some instances, phosphopreteins fractionated on gel were eluted by trypsin treatment, hydrolysed and subsequently subjected to high voltage paper electrophoresis for identification of phospho-amino acids (Ahn et al, 1985).

\section{Results}

In order to examine the system of endogenous nucleolar kinases, nucleolar phosphoproteins were labeled with $\left[{ }^{32} \mathrm{P}\right]$-phosphate under various experimental conditions.

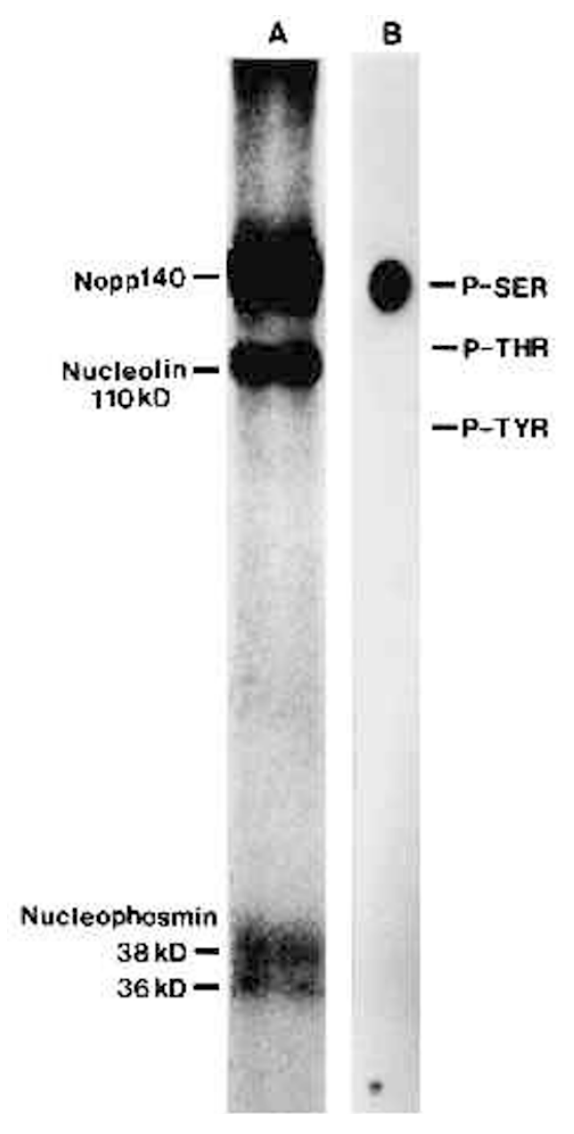

Figure 1. An analysis of an in vivo $\left[{ }^{32} \mathrm{P}\right]$-phosphate labeled nucleolar proteins from Novikoff hepatoma. A, Electrophoretic fractionation pattern of nucleolar phosphoproteins by $10 \%$ SDS-polyacrylamide gel electrophoresis; B, High voltage paper electrophoresis separation of phospho-amino acid obtained by acid hydrolysis of nucleolar phospho-proteins. Novikoff hepatoma cells were grown as a monolayer and labeled with $5 \mathrm{mCi}\left[{ }^{32} \mathrm{P}\right]$-phosphate $/ 150 \mathrm{~cm}^{2} \mathrm{~T}$ flask. Hot nucleoli were isolated by sonication and proteins were extracted with a SDS containing buffer as described in 'Materials and Methods'. 


\section{In vivo labeling of nucleolar phosphoproteins}

To establish a pattern for in vivo labeled nucleolar phosphoproteins, a whole cell labeling method was employed using cultured Novikoff hepatoma cells which were incubated overnight with $5 \mathrm{mCi}\left[{ }^{32} \mathrm{P}\right]$-phosphate/150 $\mathrm{cm}^{2} \mathrm{~T}$ flask (Ahn et al, 1985). Figure 1 shows that there were only three well defined nucleolar phosphoproteins characterized by $10 \%$ SDS-polyacrylamide gel electrophoresis, although minor proteins were observable after longer exposure. These proteins are known as major phosphoproteins and include 38/36 kDa B23/nucleophosmin, $110 \mathrm{kDa}$ C23/nucleolin and p125/Nopp140 (Ahn et al, 1985). No other well defined proteins were found. Quantitative examination of their abundance shows the highest abundance $\left(\sim 10^{6}\right.$ copies/cell $)$ in nucleophosmin, high abundance $\left(\sim 10^{5}\right.$ copies/cell) for nucleolin and mid-abundance $\left(\sim 10^{4}\right.$ copies/cell) for Nopp140. The labeling ratio observed was

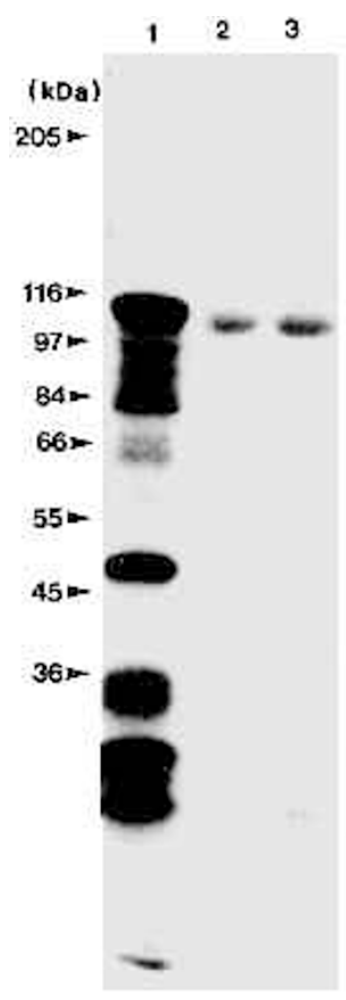

A

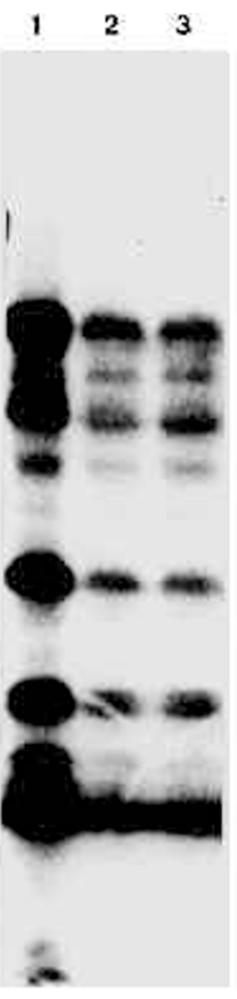

B

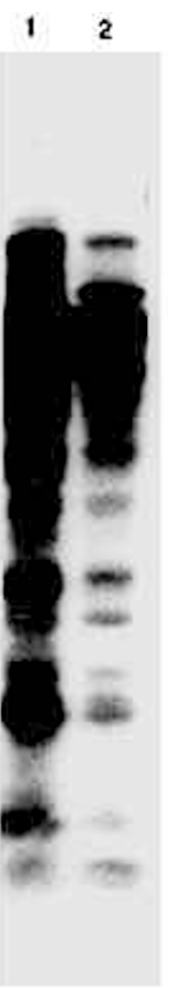

C
Figure 2. Electrophoretic fractionation patterns of in vitro [ $\left.{ }^{32} \mathrm{P}\right]$-phosphate labeled nucleolar phospho-proteins using [ $\gamma-{ }^{32}$ P]-ATP. A, normal liver; B, TA treated liver; C, Novikoff hepatoma; lane 1, control with no inhibitors; lane 2, with $200 \mu \mathrm{M}$ heparin; lane 3 , with $200 \mu \mathrm{M}$ heparin/20 $\mathrm{nM}$ protein kinase A inhibitor peptide (5-25)/20 $\mu \mathrm{M}$ protein kinase $C$ inhibitor peptide (19-31). Cold nucleoli were prepared by sonication of isolated hepatocyte nuclei and Novikoff hepatoma nuclei. Nucleoli $(10 \mu \mathrm{g})$ were incubated with $50 \mu \mathrm{l}$ of an appropriate buffer containing various kinase inhibitors.
Nopp140/nucleolin/nucleophosmin $\simeq 100 / 10 / 1$. Furthermore, when labeling was compared with other intracellular proteins, it was readily recognized that Nopp140 was the highest labeled protein among whole cell phosphoproteins (Date not shown). Thus, the nucleolus is the site of high phosphate turnover. When phospho-amino acids were analyzed on the bulk labeled proteins, only phospho-serine was found.

\section{In vivo labeling of nucleolar phosphoproteins}

When isolated nucleoli were assayed for kinases using $\left[\gamma^{32} \mathrm{P}\right]-\mathrm{ATP}$, the pattern of protein phosphorylation was very different. Figure 2 represents various labeling patterns for nucleolar phosphorylation resulting from three different nucleolar preparations including normal rat liver, thioacetamide treated liver and rapidly dividing Novikoff hepatoma cells. From these patterns, it became possible to discern different labelings among the above preparations, although the labeled proteins were fractionated by one dimensional SDS $10 \%$ polyacrylamide gel electrophoresis. The observed species totaled 11 for a normal liver, 13 for a thioacetamide treated liver and 20 for rapidly dividing Novikoff hepatoma cells. In contrast to the highest labeling protein $140 \mathrm{kDa}$ Nopp140 observed in whole cell labeling with $\left[{ }^{32} \mathrm{P}\right]$-phosphate, $110 \mathrm{kDa}$ nucleolin was the highest labeled protein observed in isolated nucleoli labeled with $\left[\gamma^{32} \mathrm{P}\right]-$ ATP. The in vitro labeling of $38 \mathrm{kDa}$ nucleophosmin was less efficient than in vivo whole cell labeling. In order to examine possible degradation during incubation at $30^{\circ} \mathrm{C}$ for $20 \mathrm{~min}$, pro-teolysis products of endogenous protease sensitive $110 \mathrm{kDa}$ nucleolin were examined by immunoblotting with anti-nucleolin antibody (Freeman et al, 1985). It was found that nucleolin degradation was not detectable under the experimental conditions applied, using various protease inhibitors. Therefore, the in vitro labeling patterns repre-sented reliable discrete molecular species with minimum proteolytic degradation. A clear difference was shown between normal liver nucleoli and thioacetamide treated liver nucleoli in labeling efficiency of molecular species larger than $66 \mathrm{kDa}$ bovine albumin. A more striking difference was demonstrated between thioacetamide treated nucleoli and rapidly dividing hepatoma nucleoli, in strong labeling of molecular species larger than $110 \mathrm{kDa}$ nucleolin. The high molecular weight phosphoproteins noted included p110 (pRb), p120 (nucleolar associated proliferative antigen), p130 (Pol I subunit), p140 (Nopp140) and p180 (topoisomerase II $\beta$ ).

\section{Study of kinase heterogeneity with inhibitors and by Western blotting}

In order to resolve the total labeling contributed by the undefined mixture of nucleolar kinases, selective inhibition studies were performed using specific protein kinase 
inhibitors. The first study inhibited casein kinase 2 using $200 \mu \mathrm{M}$ heparin $(K i=1.4 \mathrm{nM})$. With heparin, it was possible to inhibit more than $95-98 \%$ of total kinase activity (Figure 2). When an excessive concentration $(20 \mu \mathrm{M})$ of heparin was used to inhibit further, there remained approximately $1-2 \%$ of total labeling resistant to heparin. Therefore, CK2 is the major kinase molecule in the nucleolus. In order to dissect the remaining $2-5 \%$, a further inhibition study was conducted using $20 \mathrm{nM}$ protein kinase $A$ inhibitor peptide (TYADFIASGRTGRRNAI) $(K i=1.7 \mathrm{nM})$ (Glass et al, 1989) or $20 \mu \mathrm{M}$ protein kinase $\mathrm{C}$ inhibitor peptide (RFARKGALRQKNV) $(K i=200 \mathrm{nM}$ ) (Smith et al, 1990). With these inhibitors, however, clear reduction of the remaining protein kinase activity was not observed. Since this attempt to dissect the endogenous kinase mixture was not readily accomplished by the use of inhibitors, subsequent experiments were carried out to see if casein kinase 2, protein kinase $A$ and protein kinase $\mathrm{C}$ antibodies acted against them.

In order to carry out such experiments, the time course profiles of nucleolar dynamics were studied. One method was regeneration of rat liver, stimulated by the removal of $75 \%$ of liver tissue by partial hepatectomy. The surgically stimulated hepatocytes immediately exited from G0 phase and entered into a cell division cycle. This in vivo liver manipulation is known to induce $50 \%$ synchronized cell division of the entire hepatocyte population (Data not shown). The other method was to treat rat liver with a daily administration of thioacetamide (50 mg/kg) which leads to nucleolar enlargement (Jeong et al, 1994). The carcinogen treated hepatocytes showed immediate movement from G0 arrest to G2 arrest through an active DNA synthesis period. However, the cell cycle opening was not synchronous. Thus, the thioacetamide system was characterized by continuous accumulation over a week of G2 arrested hepatocytes amounting to $70 \%$ of the total hepatocyte population (Data not shown). Accor-dingly, the time course study would provide evidence of kinetic profiles of progression in the nucleolar cell cycle. Figure 3 shows representative results of immunological analysis done on casein kinase 2, PKA and PKC, where more detailed analysis of isoforms may be desirable. Figure $3 \mathrm{~A}$ shows nucleolar profiles of CK2 (70 kDa detected), PKA (40 kDa detected) and PKC (77 kDa detected) after partial hepatectomy. In the resting state liver, while CK2 was clearly detectable, PKA and PKC were barely observable. However, after $3 \mathrm{~h}$ post-thioacetamide treatment, there were increases in the amount of the three kinase molecules. The extent of increase was 3-4 fold in a $24 \mathrm{~h}$ period. Figure 3B shows a nucleolar profile after partial hepatectomy and unlike thioacetamide treated liver, regenerating liver nucleoli showed a continuous increasing accumulation of the three kinase molecules. It was found that these continuous increases were compatible with increasing nucleolar enlargement. It is clear that the predominant component is CK2 and minor components are PKA and PKC. Semiquantitative analysis of relative ratios showed grossly CK2:PKA:PKC $\simeq 30: 3: 1$. In order to eliminate possible contamination during experiments, the isolated nucleoli were repeatedly washed with saline containing $0.3 \%$ deoxycholate/1-2mM EDTA. However, the kinases were not washed out. It became clear that their presence was not due to contamination. From the above positive analytical findings, it was firmly established that the nucleolus contains the mechanisms of signaling involved in membrane-nucleolus linked signal pathways. Although further study is required to detail nucleolar signaling, the above findings provided a suitable correla-tion to the current status of signal transduction pathways (Gutkind, 1998). A proposed mechanism can be outlined by subdividing the pathways into several segmented signal steps (Figure 6).

\section{Examination of regulatory subunit $\mathbf{R}$}

In the above experiments, the regulatory subunits $\mathrm{R}$ and $\mathrm{IP}_{3} / \mathrm{Ca}^{2+}$ remained undetermined, although regulatory subunit isoform $\left(R_{\| I}\right)$ was identified. An analysis on $\mathrm{IP}_{3} /$ $\mathrm{Ca}^{2+}$ was not done because the method of nucleolar isolation employed a buffer containing $\mathrm{Ca}^{2+}$ for nuclear isolation (Busch, 1967).

The assay method of subunit $R$ was to use $\left[{ }^{32} \mathrm{P}\right]$-azido CAMP which could be covalently cross-linked under UV light (Tortora, 1990). This photo-affinity method was applied to the nucleolar preparation made from regenera-

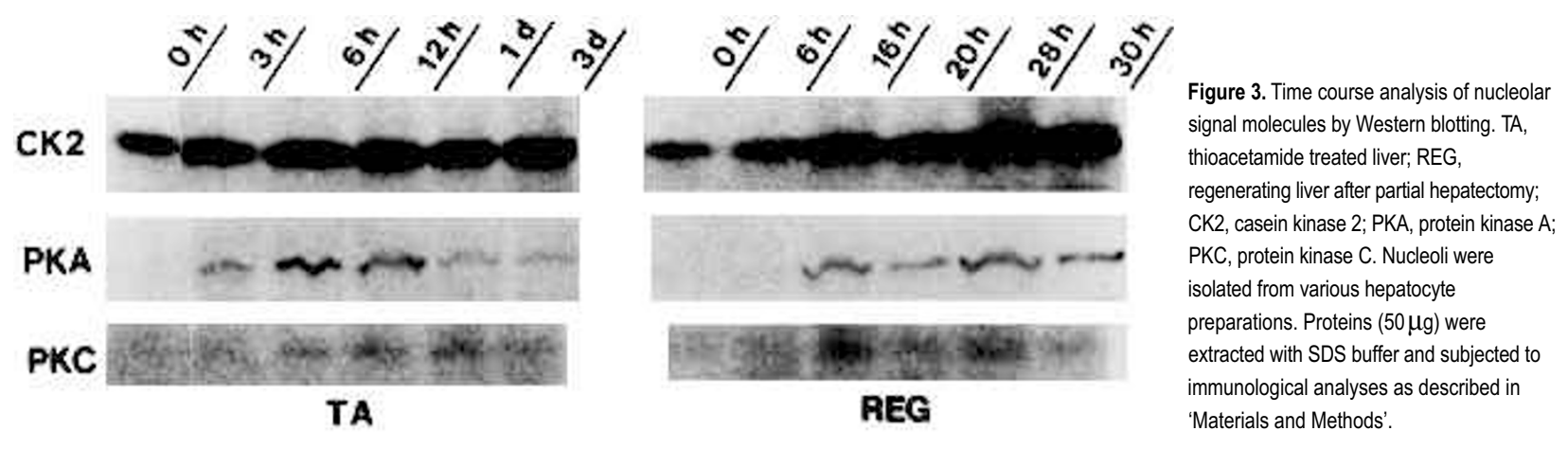




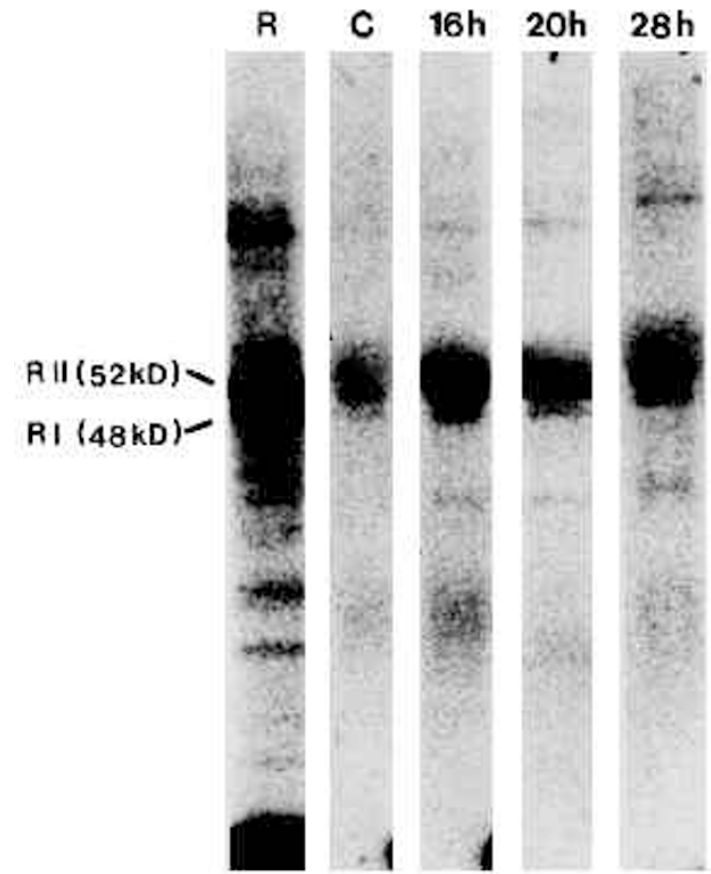

Figure 4. Time course profile of nucleolar regulatory subunits (RI/RII) after partial hepatectomy. Regulatory subunits were detected by photo-affinity labeling using $\left.{ }^{32} \mathrm{P}\right]$ azido-cAMP. R, reference markers; $C$, control; $16 \mathrm{~h}, 20 \mathrm{~h}, 28 \mathrm{~h}$, post-hepatectomy hours. Isolated nucleoli $(50 \mu \mathrm{g})$ were extracted with $100 \mu$ of a detergent buffer. $5 \mu \mathrm{Ci}\left[{ }^{32} \mathrm{P}\right]$ azido-cAMP was used to crosslink with $\mathrm{R}$ under UV light as described in 'Materials and Methods' ting rat liver after partial hepatectomy. Figure 4 presented evidence to support the presence of subunit $R$ in nucleoli. It was also found that a major isoform of the regulatory subunit was $R_{\| \mid}$type (Probably $R_{\| \beta}$ ), which showed a peak increase in the $S$ phase of hepatocyte regeneration. It is very significant to state that the nucleolar accumulation of $R_{\|}$occurred after the post-hepatectomy cell cycle activation by proliferative signals. The function of $R_{\|}$ has not been elucidated, although it has been suggested that the regulatory subunit is associated with active chromatin and involvs in regulation of transcriptional processes (Cho-Chung, 1992).

\section{Nucleolar effectors}

All the above experiments were concerned with nucleolar protein phosphorylation and the analytical definition of specific protein kinases. Based on the compiled results in Table 1, it was suggested that most nucleolar phosphoproteins contain all three motifs for CK2, PKA and PKC. It is noteworthy that the compiled motifs are only indicative and have to be substantiated by experimental definition. However, it has become clear that the nucleolar kinase cascade may represent terminal points in signal pathways and end points are associated with nucleolar function involved in pol I dependent transcription, snoRNA dependent processing and export into cytoplasm (Busch, 1997). In order to substantiate this idea, an attempt was made to question whether or not the proliferative signals observed in regeneration and thioacetamide treatment were directly associated with increases in transcription in the dense fibrillar component, and processing/export
A

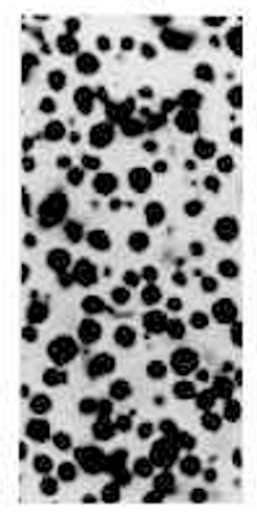

B

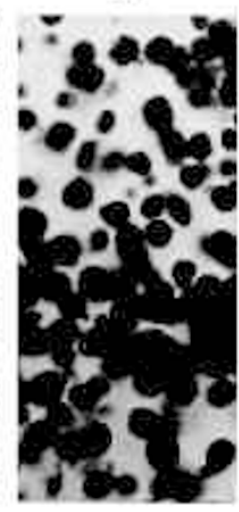

C

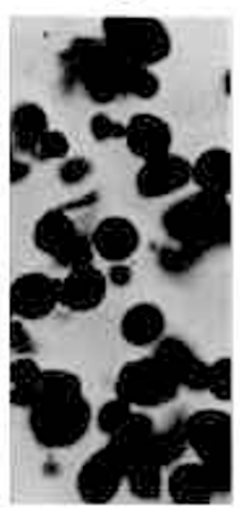

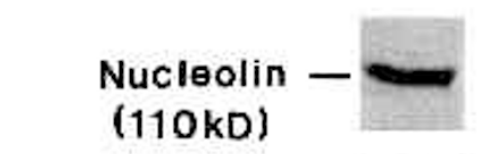

Nucleophosmin (38 kD)
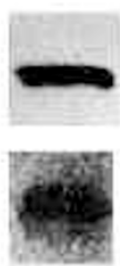
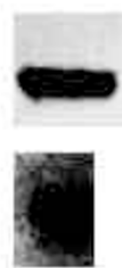

Figure 5. Examination of various nucleolar preparations obtained from normal liver(A), regenerating liver(B), thioacetamide treated liver(C). The upper large panel shows microscopic observation of isolated nucleoli. Lower panels show immunoblotting of nucleolin and nucleophosmin. See Materials and Methods for nucleolar isolation and immunoblotting. 


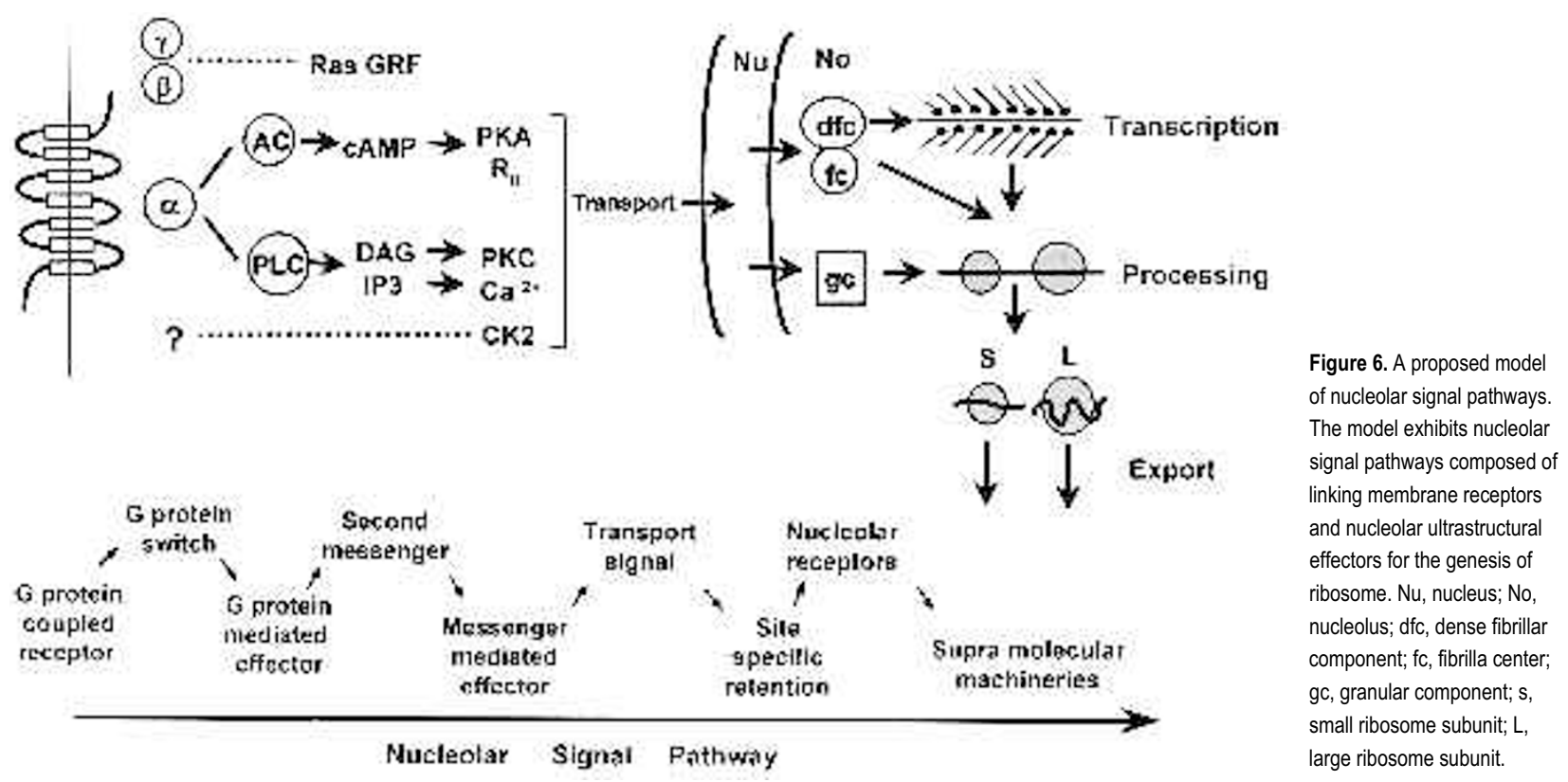

in the granular component. To represent these ultrastructural functions, two nucleolar phosphoproteins were selected for study. One was $110 \mathrm{kDa}$ nucleolin involved in transcription localized in the dense fibrillar component and the other was $38 \mathrm{kDa}$ nucleophosmin localized in the granular component. It has been shown that the two types of nucleoli from regenerating liver and thioacetamide liver are all characterized by hypertrophied substructures including granular and dense fibrillar components (Jeong et al, 1994). Figure 5 shows microscopic observations of the three different isolated nucleolar types and immunoblotting comparisons of nucleophosmin and nucleolin in the three different nucleolar preparations. It was demonstrated that there is a close relationship of increased kinase activity with enlarged nucleolar substructures. Thus, it is suggested that the nucleolar substructures are terminal effectors of membrane linked signal pathways. Further works are necessary to characterize long distance signaling links between the membrane and the nucleolus.

\section{Discussion}

The present work concludes the presence of two operational kinase systems judged by heparin sensitivity. One is the $95 \%$ predominant heparin sensitive system composed of CK2. The other, the $5 \%$ minor system of heparin resistant kinases composed of PKA, PKC and others. The latter system is inducible and observed in liver regeneration and thioacetamide induced shift from $\mathrm{G} 0$ to $\mathrm{G} 2$ arrest. For the first time, the present work demonstrated the existence of nucleolar signal pathways as an integral part of the entire whole cell signal trans- duction network system. Based on the present work, it is proposed to outline a working model which describes constituent components in cascade pathways which need to be substantiated in detail. Figure 6 shows a working model based on present experiments.

\section{Generation of secondary messengers by transduction (Gutkind, 1998)}

The identification of nucleolar $P K A / R_{\|}$and $P K C$ indicated that the membrane surface receptor is a $G$ protein coupled receptor(GPCR). Once the GPCR is activated, the $G$ protein switch is subsequently activated to act on the $G$ protein associated effectors. There are two switch associated effectors, adenyl cyclase and phospholipase $C$, which catalyze to form cAMP from ATP and diacylglyceride(DAG)/inositol triphosphate( $\left(\mathrm{IP}_{3}\right)$ from phosphoinositides, respectively. These products are the secondary messengers (Hodgkin et al, 1998), although $\mathrm{Ca}^{2+}$ release by $\mathrm{IP}_{3}$ may also be termed as a secondary messenger by some investigators.

\section{Secondary messenger mediated effectors and downstream cascades (Gutkind, 1998)}

The two types of secondary messengers thus formed proceed to activate specific downstream effectors. The first type of messenger, cAMP reacts with the inactive complex protein kinase A-regulatory subunit $\left(\mathrm{C}_{2} \mathrm{R}_{2}\right)$ which is subsequently dissociated into separate constituent subunits $(C$ and $R)$, where $C$ is the active protein kinase $A$ and $R$ is the regulatory subunit. Stoichiometry shows 
4 cAMP $\rightarrow 2 \mathrm{C}+2\left(\mathrm{R}-\mathrm{cAMP}_{2}\right)$ whereas the present work shows $R=R_{\| \mid}$(probably $R_{\| \beta}$ ). The other type of secondary messengers, DAG and IP3, activate PKC and endoplasmic reticulum to release $\mathrm{Ca}^{2+}$, respectively. These steps produce two signal molecules as in the case of cAMP. The latter post-secondary messenger effector cascades were not explored in the present study.

\section{The mobilization of signal cascade molecules and their transport into the nucleolus (Inagaki et al, 1994; Buchner, 1995; Weis, 1998)}

The number of signal cascades proceed orderly in the state of stable anchoring. It has been indicated that PKA and PKC are immobilized by anchoring signals (Dell'Acqua and Scott, 1997; Mochily-Rosen and Gardon, 1998). Therefore, to transport anchored signal molecules in cytoplasm requires several mechanisms.

a) Anchored signal molecules must be released by deanchoring mechanisms.

b) The released molecules are carried by transport protein(s) into nucleoli. Once within the nucleoli, specific signals are required to distribute the sub-nucleolar compartments with specific nucleolar retention signals. It is added that there are unidentified selective mobilization mechanisms in the cascade phospholipase $\mathrm{C} \rightarrow \mathrm{IP}_{3} \rightarrow$ $\mathrm{Ca}^{2+}$ where any of the signals can become transportable (Manzoli et al, 1995 and Malviga and Rogue, 1998). This mechanism was not tested in the experiments.

\section{Nucleolar effectors}

The nucleolus is the site of ribosome genesis and functional sites are subdivided into supramolecular machineries composed of pol I dependent transcription, pre-rRNP assembly, snoRNA dependent pre-rRNA processing and RNP export (Busch, 1997). The ultrastructural studies indicate the presence of a high abundance $\left(\sim 10^{5}\right.$ copies/ cell) of $110 \mathrm{kDa}$ nucleolin in the dense fibrillar component for transcription and the highest abundance $\left(\sim 10^{6}\right.$ copies/ cell) of $38 \mathrm{kDa}$ of nucleophosmin in granular components for RNA processing and transport. Both protein species contain three kinase motifs; CK2, PKA and PKC.

Why is the major kinase CK2 important? Why is the minor kinase PKA and PKC important? What is the functional relationship between the major constituent CK2 and the minor inducible PKA/PKC? The present work provides no clear answer for these fundamental questions. However, the work presents suggestive evidence that shows a close relationship of PKA/PKC induction to cell cycle opening. This relationship has been similarly observed in other cell types in response to various growth factors. For example using in vitro labeling techniques, PKA dependent nucleophosmin phosphorylation was observed in insulin stimulated $\mathrm{NIH}$
3T3 HIR cells (Feuer-stein and Randazzo, 1991), while PKC dependent nucleolin phosphorylation was identified in PC12 cells, stimulated by nerve growth factors (Zhou et al, 1997). Thus, additional modifications although minor appear to reflect subtle structural arrangements both in the dense fibrillar component, containing nucleolin, and in the granular component containing nucleophosmin. Since these are related to cell cycle opening, it is most likely that very fine tuning is generated by nucleolar chromo-somal remodeling.

To summarize it is concluded that the present report provides evidence for a system of nucleolar signaling pathways composed of membrane receptors $\rightarrow \mathrm{G} \alpha s \rightarrow$ secondary messengers $\rightarrow$ PKA/R $R_{\|}$and PKC $\rightarrow$ translocation into nucleolar compartments.

\section{Acknowledgement}

This work was supported in part by grants from the Basic Medical Research Fund of the Ministry of Education of Korea (1994), and the Korea Science and Engineering Foundation (KOSEF 92-2400-11-01-3).

\section{References}

Ahn, Y. S., Choi, Y. C., Goldknopf, I. L. and Busch, H. (1985) Isolation and characterization of a 125-kilodalton rapidly labeled nucleolar phos-phoprotein. Biochemistry 24: 7296-7302

Bagrodia, S., Derijard, B., Davis, R. J. and Cerione, R. A. (1995) Cdc42 and PAKmediated signaling leads to Jun kinase and p38 mitogen-activated protein kinase activation. J. Biol. Chem. 270: 27995-27998

Buchner, K. (1995) Protein kinase $C$ in the transduction of signals toward and within the cell membranes. Eur. J. Biochem. 228: 211-221

Busch H. (1967) Isolation and purification of nucleoli. Methods Enzymol., XII, part A, pp. 448-464

Busch, H. (1997) Nucleolar and nucleolonemal proteins of cancer cells. J. Tumour Marker Oncol.

Cho-Chung, Y. S. (1992) Modulation of adenylcyclase signalling. Cancer Biol. 3: 361367

Dell'Acqua, M. L. and Scott, J. D. (1997) Protein kinase A anchoring. J. Biol Chem. 272 12881-12884

Diehl, A. M. and Rai, R. M. (1995) Regulation of signal transduction during liver regeneration. FASEB J. 10: 215-227

Feuerstein, N. and Randazzo, P. A. (1991) In vivo and in vitro phosphoryl-ation studies of numatrin, a cell cycle regulated nuclear protein, in insulin-stimulated NIH $3 T 3$ HIR cells. Exp. Cell Res. 194: 289-296

Freeman, J. W., Chatterjee, A., Ross, B. and Busch, H. (1985) Epitope distribution and immunochemical characterization of nucleolar phospho-protein $\mathrm{C} 23$ using ten monoclonal antibodies. Mol. and Cell Biochem. 68: 87-96

Glass, D. B., Cheng, H. C., Mende-Mueller, L., Reed, J. and Walsh, D. A. (1989) Primary structural determinants essential for potent inhibition of cAMP-dependent protein kinase by inhibitory peptides corresponding to the activity portion of the heatstable inhibitor protein. J. Biol. Chem. 264: 8802-8809

Goldknopf, I. L. and Busch, H. (1978) Modification of nuclear proteins: the ubiquitin- 
histone A conjugate. The Cell Nucleus, Chromatin Part C, Vol. VI, pp. 149-180

Goldknopf, I. L., Rosenbaum, F., Sterner, R., Vidali, G., Alfrey, V. G. and Busch, H. (1979) Phosphorylation and acetylation of chromatin conjugate protein A24. Biochem. Biophys. Res. Comm. 90: 209-227

Gutkind, J. S. (1998) The pathways connecting G protein-coupled receptors to the nucleus through divergent mitogen-activated protein kinase cas-cades. J. Biol. Chem. 273: 1839-1842

Higgins, G. M. and Anderson, R. M. (1931) Experimental pathology of liver. Arch Pathol. 2: 186-202

Hodgkin, M. N., Pettit, T. R., Martin, A., Michell, R. H., Pemberton, A. J. and Wakelam, M. J. O. (1998) Diacylglycerols and phosphatidates: which molecular species are intracellular messengers? TIB 23: 200-204

Inagaki, N., Ito, M., Nakano, T. and Inagaki, M. (1994) Spatiotemporal distribution of protein kinase and phosphotase activities. TIB 19: 448-452

Jeong, J. S., Kang, H. J., Lee, H. J. and Choi, Y. C. (1994) Types of nucleolar hypertrophy in rat liver. Mol. Cells 4: 85-90

Kleinfeld, R. G. (1952) Early changes in rat liver and kidney cells induced by thioacetamide. Cancer Res. 17: 954-962

Laemmli, U. K. (1970) Cleavage of structural proteins during the assembly of the head of bacteriophage T4. Nature 227: 680-683

Lischwe, M. A., Cook, R. G., Ahn, Y. S., Yeoman, L. C. and Busch, H. (1985) Clustering of glycine and $N^{G}, N^{G}$-dimethylarginine in nucleolar protein C23. Biochemistry 24: 60256028
Malviya, A. and Rogue, P. J. (1998) Tell me where is calcium bred: clari-fying the roles of nuclear calcium. Cell 92: 17-23

Manzoli, L., Billi, A. M., Gilmour, R. S., Martelli, A. M., Matteucci, A., Rubbini, S., Weber, G. and Cocco, L. (1995) Phosphoinositide signaling in nuclei of Friend cells: Tiazofurin down-regulates phospholipase $C_{\beta}$. Cancer Res. 55: 2978-2980

Meck, D. W. and Street, A. J. (1992) Nuclear protein phosphorylation and growth control. Biochem. J. 287: 1-15

Mochily-Rosen, D. and Gardon, A. S. (1998) Anchoring protein for protein kinase C: a means for isozyme selectivity. FASEB J. 12: 35-42

Olson, M. O., Orrick, L. R., Jones, C. and Busch, H. (1974) Phosphorylation of acid-soluble nucleolar proteins of Novikoff hepatoma ascites cells in vivo. J. Biol. Chem. 249: 28232827

Smith, M. K., Colbran, R. J. and Soderling, T. R. (1990) Specificity of autoinhibitory domain peptides for four protein kinases. J. Biol. Chem. 265: 1837-1840

Tortora, G., Clair T. and Cho-Chung, Y. S. (1990) An antisense oligodeoxy-nucleotide targeted against the type $\|_{\beta}$ regulatory subunit mRNA of protein kinase inhibits CAMPinduced differentiation in $\mathrm{HL}-60$ leukemia cells without affecting phorbol ester effects. Proc. Natl. Acad. Sci. USA 87: 705-708

Towbin, H., Staehelin, T. and Gordon, T. (1979) Electrophoretic transfer of proteins from polyacrylamide gels to nitrocellulose sheets, procedure and some applications. Proc. Natl. Acad. Sci. USA 76: 4350-4355

Weis, K. (1998) Importins and exportins: how to get in and out of the nucleus. TIBS 23: $185-189$

Zhou, G., Seibenhener, M. L. and Wooten, M. W. (1997) Nucleolin is a protein kinase C $\zeta$ substrate. J. Biol. Chem. 272: 31130-31137 